Artículos Científicos

\title{
Crítica al concepto de liderazgo en la teoría administrativa norteamericana
}

\author{
Criticizes the concept of leadership in american administrative theory \\ Critica o conceito de liderança na teoria administrativa americana
}

\author{
Francisco Ballina Ríos \\ Universidad Nacional Autónoma de México, México \\ fballina@fca.unam.mx \\ https://orcid.org/0000-0003-2739-9245
}

○ Existe una versión precedente de este artículo (Ballina, 1996, 2001).

\section{Resumen}

Este artículo surge a partir de estas interrogantes: ¿es lo mismo dirección y liderazgo?, ¿existen diferencias o semejanzas?, y ¿cuáles son? Para intentar dar respuesta se analizan las características y variaciones de diferentes enfoques dentro de la teoría administrativa norteamericana del liderazgo, de la cual se reconocen sus alcances y limitaciones. Asimismo, se plantean las diferencias entre líderes y administradores, entre los siervos del poder y los servidores públicos, para considerar finalmente la posibilidad de una teoría alternativa del liderazgo que supere los límites del liderazgo individual ausente de consideraciones éticas y colectivas.

Palabras clave: dirección, liderazgo, mitos y estereotipos, teoría administrativa. 


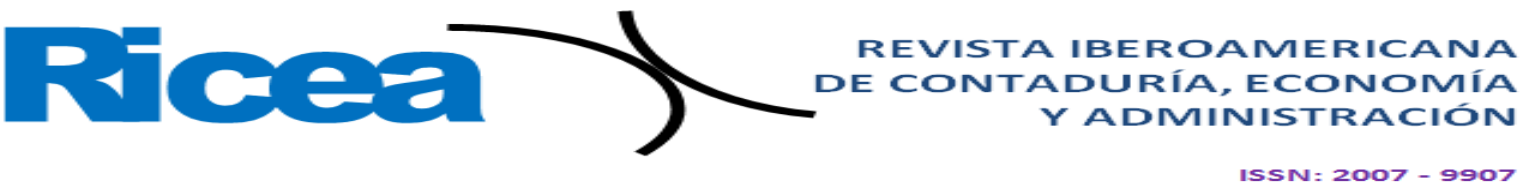

\begin{abstract}
This article raises some critical questions about the administrative theory of leadership: is it the same direction and leadership? Are there differences or similarities? In addition, what are they? The characteristics and variations of different approaches within the conventional theory of leadership, recognizing its scope and limitations, these questions framed in the differences of community, patrimonialism and bureaucratic administration. Likewise, the differences between leaders and administrators, between the servants of power and public servants, and finally consider the possibility of an alternative theory of leadership that exceeds the limits of individual leadership absent from collective considerations.
\end{abstract}

Keywords: Direction, leadership, myths and stereotypes, administrative theory.

\title{
Resumo
}

Neste artigo, algumas questões críticas são levantadas em torno da teoria administrativa da liderança: é a mesma direção e liderança? Existem diferenças ou semelhanças? E quais são? As características e variações de diferentes abordagens dentro $\mathrm{Na}$ teoria convencional da liderança, reconhecendo seu escopo e limitações, essas questões estão enquadradas nas diferenças de administração comunitária, patrimonialista e burocrática. Da mesma forma, as diferenças entre líderes e administradores, entre os servidores do poder e os servidores públicos, são levantadas para finalmente considerar a possibilidade de uma teoria alternativa da liderança que exceda os limites da liderança individual ausente de considerações coletivas.

Palavras chave: Direção, liderança, mitos e estereotipos, teoria administrativa.

Fecha Recepción: Junio $2021 \quad$ Fecha Aceptación: Diciembre 2021

\section{Introducción}

Dada la ambigüedad en el uso de los conceptos dirección y liderazgo dentro de la teoría administrativa norteamericana, surgen las siguientes interrogantes: ¿son equivalentes la dirección y el liderazgo?, ¿cómo transcurre el liderazgo en la dominación carismática, tradicional y burocrática?, ¿cuáles son las características y variaciones de la teoría convencional del liderazgo?, ¿existen diferencias de dirección y liderazgo en empresas y organizaciones corporativas y cooperativas?, ¿Es posible postular una teoría del liderazgo que incorpore consideraciones éticas y colectivas? 


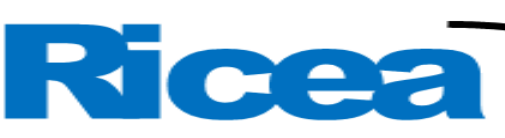

REVISTA IBEROAMERICANA DE CONTADURÍA, ECONOMIIA YADMINISTRACIÓN

ISSN $=2007-9907$

Para intentar dar respuesta a estas interrogantes se ha planteado un análisis críticohermenéutico, con base en la heurística a partir de la sociología política. La metodología utilizada, a grandes rasgos, es analítica deductiva, basada en un respaldo de investigación documental desde la perspectiva del poder y la dominación, conceptos analíticos con los que se inicia esta crítica.

\section{Marco teórico-conceptual}

En los estudios de las ciencias sociales se construyen conceptos que tienen cierta utilidad clasificatoria, terminológica y humanística, aunque en la mayoría de los casos son construcciones típico-ideales que proceden de aproximaciones convencionales. Conceptos como empresa, organización, sociedad anónima, administración o liderazgo son representaciones que en parte existen y en parte se convierten en un deber ser, o en lo que no debe ser (Ballina, 2019).

El Diccionario de la Real Academia Española define el vocablo liderazgo del siguiente modo: “Condición de líder. Ejercicio de las actividades del líder. Situación de superioridad en que se halla una institución u organización, un producto o un sector económico, dentro de su ámbito"; mientras que la palabra dirección deriva del término latino dirigere, de regere ('regir'), es decir, enviar una cosa a cierto punto o en cierta dirección, acción de conducir, guiar o regir, o "proceso de influir en las personas para que contribuyan a los objetivos y metas de la organización” (Moliner, 1994, p. 1008).

La teoría administrativa norteamericana adoptó el concepto liderazgo como sinónimo de dirección, es decir, elemento racional a través del cual se alcanza todo lo planeado. Asimismo, gracias a la autoridad y a la coordinación, se le concibe como el proceso de influir en las actividades de los miembros del grupo mediante la motivación, la comunicación y la supervisión (Argyris, 1978; Lewin, 1951, 1968; McGregor, 1969).

Entre los precursores modernos de la administración encontramos a Adam Smith (1976), quien empleó el término dirigir como la forma de realizar el proceso de operación y desarrollo de una empresa. Posteriormente, John Stuart Mill (2008) se refirió a este como la acción de delegar el manejo de la empresa en personas que no son los dueños.

Dentro de la denominada teoría clásica de la administración (fines del siglo XIX), Taylor (1973) vinculó el vocablo dirección no solo con el proceso de producción, sino también con quienes lo realizan. Asimismo, consideraron que su objeto de estudio estaba 


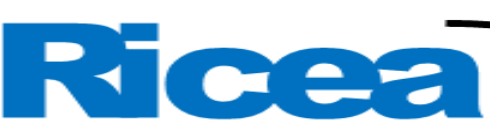

REVISTA IBEROAMERICANA DE CONTADURÍA, ECONOMÍA YADMINISTRACIÓN

ISSN $=2007-9907$

centrado en la organización formal, la cual debe ser regulada por principios y concebida a través de sus áreas funcionales, donde el hombre es percibido como engrane de una máquina.

Por otra parte, la administración científica — concepto acuñado por Taylor (1973)— se basó en estudios de tiempos y movimientos. Establecía que el método científico podía ser aplicado en la selección, adiestramiento y capacitación de los trabajadores para lograr un nivel de eficiencia en la producción. Este autor la define como "ciencia, y no regla empírica; armonía, y no discordia; colaboración, y no individualismo; rendimiento máximo, en lugar de rendimiento restringido; formación de cada hombre hasta alcanzar su mayor eficiencia y prosperidad" (Taylor, 1973, p. 121).

Asimismo, el dirigir al personal en las organizaciones - denominado mandar por Fayol (1973) — se consideraba como la parte vital de la administración. La buena o mala dirección existe y tiene su influencia en el desarrollo de empresas y organizaciones, pero las características y el análisis del liderazgo no se enuncian con precisión en la teoría clásica de la administración.

No es necesario presentar muchas pruebas documentales para constatar que la disciplina militar es el modelo ideal de la empresa capitalista, el cual es adoptado por Taylor (1973). Este fenómeno universal limita paulatinamente la importancia del líder carismático, mientras que el comportamiento individual decrece como poder creativo. En instituciones duraderas, tanto en la empresa como en el aparato estatal burocrático, este proceso va unido a una concentración de los medios materiales de organización bajo la autonomía de un directivo o mandatario.

En la teoría clásica, la dirección científica se basaba en la sustitución del control, que se hallaba en manos de los trabajadores, además de un director que diera órdenes, dirigiera el trabajo y supervisara los resultados. Para establecer el control por parte de la dirección deberían simplificarse las tareas por medio de tiempos y movimientos.

En la década de los treinta, los experimentos de Elton Mayo y sus colaboradores (1946) pusieron de manifiesto las limitaciones de la administración científica. Estudiosos del comportamiento — como Lewin (1951, 1969), Argyris \& Schön, (1978) y McGregor (1969) - recomendaron dar mayor participación a los trabajadores en la toma de decisiones, de lo cual surgió la confusión entre los conceptos líder y jefe, gerente y directivo. 


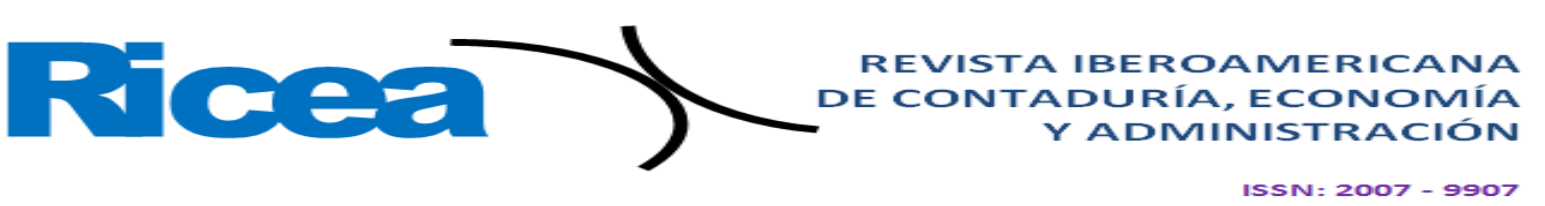

\section{Variaciones en la teoría del liderazgo}

El concepto liderazgo dentro de la teoría administrativa norteamericana se dirige a la búsqueda del "liderazgo efectivo" para lograr el "éxito". El líder es capaz de coordinar y de equilibrar conflictos entre individuos y grupos, así como de superar las crisis y tomar las decisiones para hallar una solución. Las diferencias entre estas teorías radican en supuestos básicos que a continuación se sintetizan.

En términos generales, los modelos de liderazgo en la teoría administrativa norteamericana presentan tres enfoques: 1) de rasgos, 2) de comportamientos y 3) de contingencias, todos los cuales derivan de la "dirección científica", "dirección participativa" o "dirección por contingencias".

El enfoque de los rasgos del liderazgo se basa en la teoría del "gran hombre", según la cual los líderes nacen, y no se hacen, idea que data de la época de los antiguos griegos y romanos. Por otra parte, los investigadores han tratado de identificar las características físicas, mentales y de personalidad de diversos líderes. La gran limitante de este enfoque es que ni los grandes rasgos ni las características de los líderes son permanentes ni universales, pues la devoción individual o el culto del honor dependen de circunstancias geográficas y culturales.

El enfoque del comportamiento se basa en la escuela conductista de psicología, y se inicia con los experimentos que realizó Elton Mayo, entre 1929 y 1945, en la Western Electric Company. Su libro — The social problems of an industrial civilitation (1946) - puso de manifiesto algunos de los costos sociales y empresariales de la administración científica de Taylor y Fayol. Otra figura destacada en este movimiento fue Lewin (1951, 1969), quien manifestó la eficacia de la participación del trabajador en la toma de decisiones.

Luego, en las décadas de los cincuenta y los sesenta, estudiosos del comportamiento decepcionados por los métodos tradicionales - como Argyris, McGregor y Likertbrindaron sus versiones de la dirección participativa de empresas.

En el enfoque del comportamiento, Likert (1967) estudió los patrones y estilos de líderes y administradores para comprender la conducta del liderazgo. Estos investigadores consideraron que el administrador eficiente era aquel que orientaba intensamente sus acciones hacia los subordinados y que se apoyaba en la comunicación para mantener en funcionamiento, como una unidad, a todas las divisiones de la empresa. 


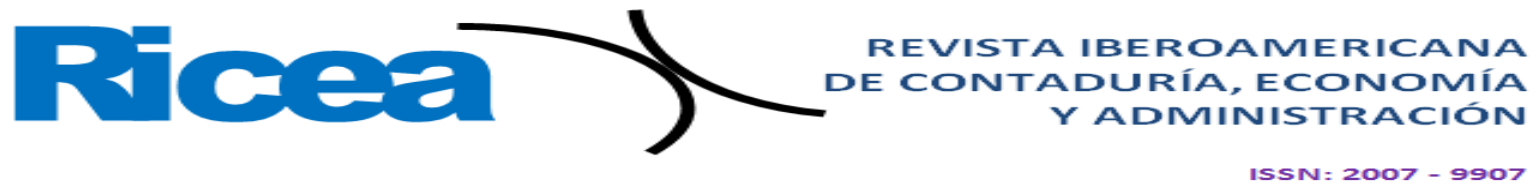

La teoría Y de McGregor y la del estilo 9-9 de liderazgo de Blake (1964) son postulados no contingentes, y comparten la opinión de que existe una postura de dirección que es la mejor y universal en sus aplicaciones. Schreiber (1969) en su best-seller El desafío americano consideraba que sus métodos de dirección eran un modelo que el resto del mundo debía copiar. Las condiciones estables y de rutina parecen asociarse generalmente a una supervisión autoritaria y rigurosa. Las conclusiones de estas investigaciones sugieren que un "líder" orientado a la tarea es más apropiado para las condiciones de "dirección científica" tayloriana, en donde las ideas de participación del trabajador, el compromiso de los empleados y la democracia en el medio laboral no figuran en los métodos de trabajo.

Sin embargo, las condiciones que rápidamente cambian sugieren que la dirección orientada a las personas por parte del administrador puede ser efectiva. Leavit (1951) decía que el taylorismo había pasado a ser la filosofía empresarial dominante en los niveles más bajos; así los obreros de las cadenas de montaje, los cajeros, las secretarias y similares están sujetos a tiempos y movimientos. Aquí el taylorismo gana la batalla.

En los niveles medios y altos se puede introducir la dirección participativa, aumentar la intervención de los trabajadores, "los círculos de calidad", los grupos de trabajo autogestionarios y los equipos de alto rendimiento, mecanismos que aspiran a mejorar la productividad mediante una mayor participación del trabajador. El dilema entre dirección científica y dirección participativa, según esta teoría, es un problema de asignación al puesto, pues las posiciones y labores cambian, y el eje de la dirección es mantener el equilibrio.

En términos generales, las teorías de dirección participativa y los modelos de carácter simplista —como los de Likert (1961), la teoría Y de McGregor (1969) o la teoría de Ouchi (1981) - generan escepticismo al intentar aplicar sus recetas universales a la realidad mexicana, la cual nos enseña que las soluciones son más difíciles, por no decir inalcanzables.

Lo que se cuestiona, por tanto, es el nivel de motivación o satisfacción que obtienen los trabajadores con la aplicación de estos modelos. Al realizar un examen de las principales teorías sobre la motivación y los motivadores, hoy en día apenas se hace referencia a la zanahoria y la vara, alegoría que se sigue aplicando indiscriminadamente en estos modelos organizacionales.

El reemplazo del argumento del 9-9 ("un estilo para todas las ocasiones") ocurre con el liderazgo situacional. Las limitaciones de la "dirección participativa" consisten en que no se toma en consideración el tipo o tamaño de las organizaciones ni la incertidumbre ambiental causada por los cambios políticos, tecnológicos, socioculturales y económicos, o las 


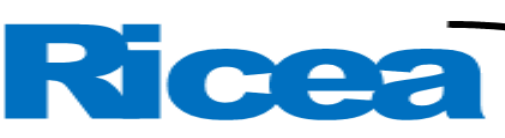

REVISTA IBEROAMERICANA DE CONTADURÍA, ECONOMÍA YADMINISTRACIÓN

ISSN= $2007-9907$

diferencias individuales (valores, ambiciones, autonomía, tolerancia). Las contingencias son sucesos o circunstancias que se presentan de manera imprevista. Así, la teoría contingencial establece esta relatividad situacional.

Si bien Maquiavelli (1969) — basado en Aristóteles (trad. 1984)— había reflexionado en esta relatividad circunstancial al desarrollar la teoría del péndulo, la idea de que la corrupción de las instituciones democráticas hace necesaria la restauración de las dictaduras divide las formas de gobierno en puras e impuras. Las primeras son la monarquía, la aristocracia y la república, mientras que las segundas son la tiranía, la oligarquía y la demagogia. De las tres formas puras, la mejor será aquella que cuente con los mejores jefes, sea este un individuo de superior virtud, sea una raza o una multitud, especialmente cuando la virtud pública coincide con la privada.

Vroom y Yetton (1973) desarrollaron un modelo de "líder-participación" que relaciona el comportamiento del liderazgo y la participación con la toma de decisiones. El modelo buscaba ser normativo e identificaba cinco estilos alternativos del "liderazgo" en una situación determinada: autocrático I (AI), autocrático II (AII), consultor I (CI), consultor II (CII) y grupo II (GII). Este modelo intentaba probar que la investigación sobre el "liderazgo" debía enfocarse en la situación antes que en la persona.

Blake (1964), utilizando la rejilla —o grid gerencial- reconoce tres tipos de administraciones: empobrecida, de equipo y de club campestre. En la primera se preocupan muy poco por las personas y se concentran en la producción. En la segunda se armonizan las necesidades de los individuos con la producción. Y en la tercera existe poca o nula preocupación por la producción, por lo que solo se interesan por las personas.

Fiedler (1967) establece un test, engañosamente simple, que requiere que los directores piensen en la persona "con la que no les gustaría trabajar" por ser sospechoso de pereza o ineptitud. A dicha persona se le da la puntuación con adjetivos tales como agradable, desagradable o simpático, antipático. Fiedler (1967) llama a esta medida la escala del compañero de trabajo menos preferido, a quien sus compañeros asignan adjetivos desfavorables.

Asimismo, Fiedler descubrió que los líderes motivados por las relaciones tienen más éxito en situaciones moderadamente favorables. Por el contrario, los motivados por el trabajo suelen alcanzar mayores éxitos tanto en situaciones muy desfavorables como en las muy favorables. Fiedler, por tanto, llega a la conclusión de que los autócratas son mejores para situaciones extremas (muy favorables o muy desfavorables), en tanto que los directores 


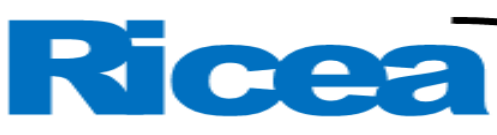

REVISTA IBEROAMERICANA DE CONTADURÍA, ECONOMIIA YADMINISTRACIÓN

ISSN : $2007-9907$

participativos son mejores cuando la situación no es extremadamente favorable o desfavorable.

Las deficiencias de este modelo, además de su simplismo, son que no incluyen normas para el desempeño eficaz de los directores. No existe un "liderazgo" efectivo o único, el cual depende del "líder", de los "seguidores", de la situación e interrelación entre ellos.

Tannenbaum y Schmidt (1958) continúan con la confusión entre liderazgo y dirección. Ellos se enfocan en la naturaleza situacional de la eficiencia del "líder", que se ubica en tres dimensiones situacionales: a) relación líder-miembro, b) poder de influencia y c) estructura grupo-tarea. Para House y Browdith (1980) un "liderazgo efectivo" depende de las recompensas personales a los subalternos por la obtención de metas de trabajo y de establecer el camino hacia esas recompensas.

El modelo de liderazgo de contingencias de Hersey y Blanchard (1982) se enfoca en la madurez de los seguidores como dispositivo principal para determinar los cuatro tipos específicos de liderazgo que ellos identifican: comunicar, vender, participar y delegar. En el primer caso, el líder define los roles y papeles: dice a la gente qué, cómo, cuándo y dónde desarrollan sus actividades. En la segunda etapa, el "líder" proporciona tanto un comportamiento directriz como uno de apoyo. Una vez que se logra la participación en la toma de decisiones, a través de la comunicación, el "líder" podrá finalmente delegar.

En términos generales, los modelos contingenciales de liderazgo surgen dentro de las estructuras formales de las empresas, si bien estos superan las deficiencias de la "dirección científica" y la "dirección participativa" que se basan en estas teorías. Incluso cuando reconocen la complejidad del entorno, las conclusiones de estos modelos al aportar soluciones demasiado simples para problemas complejos resultan dudosos. La deficiencia general es que estos modelos reconocen solo las contingencias primitivas que simplifican al máximo la complicada naturaleza de los grupos humanos.

Desde la perspectiva occidental, particularmente la norteamericana, las teorías administrativas han tenido como idea central la de que el individuo, y no la sociedad, debe constituir el fin fundamental, idea que animó, antes de la revolución industrial, al calvinismo y el puritanismo. El conflicto entre el individuo y la sociedad siempre ha entrañado un dilema que implica la concepción del aprendizaje colectivo en la empresa y la organización, si bien en el contexto norteamericano esta educación se basa en principios utilitarios. 


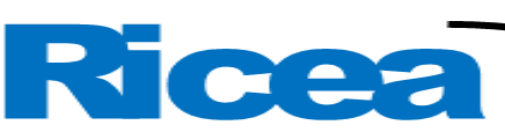

REVISTA IBEROAMERICANA DE CONTADURÍA, ECONOMIIA YADMINISTRACIÓN

ISSN $=2007-9907$

Zaleznik (1986) estableció la distinción entre administradores y líderes, los cuales interactúan para establecer estrategias y toma de decisiones. Este autor menciona que una sociedad burocrática que engendra gerentes puede estar ahogando a los líderes jóvenes, de ahí que se pregunte por qué existe conflicto: ¿no pueden existir los gerentes y los líderes dentro de la misma sociedad?, ¿puede una sola persona ser gerente y líder?, ¿acaso el dilema es que los administradores y líderes son dos tipos de personas diferentes en cuanto a desarrollo, historia personal, motivaciones y manera de pensar?

Los administradores tienden a adoptar actitudes impersonales y pasivas ante las metas. Los líderes conciben sus metas; son activos en lugar de reactivos y conforman ideas en lugar de responder a ellas. La influencia que ejerce un líder para alterar estados de ánimo, evocar imágenes, esperanzas y establecer objetivos específicos en el curso de las decisiones no la concreta el gerente o las personas que desempeñan cargos o puestos formales. En otras palabras, el líder se convierte en tal por su reconocimiento moral, mientras que el director lo logra por tozudez.

La teoría norteamericana de la administración considera que la esencia del liderazgo organizacional consiste en aumentar la influencia por arriba del nivel de obediencia mecánica a las órdenes rutinarias, y que todo grado de influencia en cuestiones de índole organizacional corresponde al "liderazgo". La teoría norteamericana de la organización (Parker et al., 1942) — considera a la organización como un sistema complejo de toma de decisiones, como un sistema de interacciones de actividades y sentimientos (Homans, 1950) e incluso como un sistema cerrado o abierto o de contingencias.

Hay evidencias de que la teoría neoclásica de la administración no ha superado el escollo de la clásica, en términos de considerar al trabajador como simple engrane de una máquina. Los interaccionistas (Mayo, 1946, 19898) se interesaron exclusivamente en el mundo de las interacciones-sentimientos como respuesta de productividad al condicionamiento económico del salario y del rendimiento, que es una propuesta de la administración científica de Taylor. Si se demuestra que la conducta afectiva se halla sujeta a una serie de factores controlables, es difícil no usar dicho conocimiento para tratar de manipular a los trabajadores y desentenderse, igual que los clásicos, de los problemas del poder y la dominación (Ballina, 2019).

Lewin (1968) (en la teoría de los grupos) quería demostrar que existía una relación constante y unívoca entre la satisfacción individual, la productividad y un estilo de liderazgo permisivo. Además, continuaron desconociendo las relaciones de poder y explotación que se 


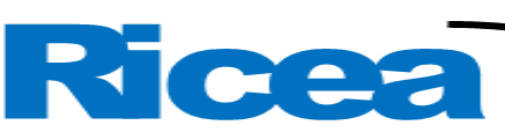

REVISTA IBEROAMERICANA DE CONTADURÍA, ECONOMÍA YADMINISTRACIÓN

ISSN $=2007-9907$

anudan alrededor de la pirámide jerárquica, y sin las cuales esta solo aparece en un marco puramente formal. Sin duda, al atraer la atención hacia los problemas de la participación, los seguidores de Lewin (1968) introdujeron una veta de investigación que se ha revelado fecunda, pero también se encerraron en una pauta de interpretación muy estrecha, que no les permite comprender las fuerzas actuantes dentro de las organizaciones.

Kahn et al. (1964) creen que se pueden llegar a coordinar las actividades humanas en el seno de una organización para obtener el máximo necesario de aceptación utilizando estímulos económicos o ideológicos. Se busca así la perfecta productividad y un equilibrio entre los fines de la organización y la satisfacción individual de sus miembros. Utilizando un sistema "permisivo" de mando, en esta teoría tampoco es necesario estudiar los problemas del poder: basta con luchar por que el aparato de mando no se desintegre.

Michels (1974) y Mannheim (1982) son los primeros en destacar el dilema en que se encuentran forzosamente las burocracias modernas que quieren lograr profundas transformaciones sociales, sean reformistas o revolucionarias. La acción social no es posible sino a través de organizaciones (es decir, burocracia), pero la existencia de estas es incompatible con los valores democráticos que son los únicos que hacen legítima la acción social.

Al respecto, se destaca la opinión de Barnard (1959), quien conceptualiza la organización como un sistema social cooperativo; es decir, como un sistema de actividades o fuerzas sociales, biológicas y físicas conscientemente coordinadas, cuyo balance tanto interno como externo debe mantenerse en equilibrio.

No obstante, cualquier acción cooperativa coordinada exige que cada participante pueda contar con un grado de regularidad suficiente por parte de los demás. Esto significa, en otras palabras, que toda organización - cualquiera que sea su estructura, su objetivo y su importancia - requiere por parte de sus miembros una conformidad mayor o menor, pero siempre considerable y obtenida en parte por compulsión, apelando a la "buena voluntad".

El burocrático no es solamente un universo que no se corrige en función de sus errores, sino que es incapaz de transformarse conforme a la evolución acelerada de las sociedades, como lo muestra el nihilismo llevado a sus consecuencias más extremas en las proyecciones simbólicas típicas de Kafka.

Dentro de una visión sistemática (Michel, 1974), la organización debe concebirse como un sistema abierto, esto es, con múltiples relaciones con el ambiente. También debe entenderse como un esquema con múltiples propósitos o funciones necesarias para integrar 


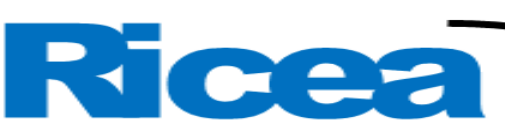

REVISTA IBEROAMERICANA DE CONTADURÍA, ECONOMÍA YADMINISTRACIÓN

ISSN $=2007-9907$

y coordinar, que implica muchos subsistemas en interacción dinámica. Y dado que los subsistemas son mutuamente dependientes, sus cambios afectarán el comportamiento de los demás. Las múltiples relaciones entre la organización y su ambiente hacen difícil especificar de manera clara las fronteras de una entidad dada.

Desde el punto de vista del enfoque sistémico, las organizaciones son concebidas como estructuras ordenadas, y esta predisposición alienta el funcionalismo que conceptualiza la realidad dentro de un marco altamente estático y mecanicista. Desde finales de la Segunda Guerra Mundial hasta los últimos años de los setenta, el consenso teórico y metodológico de los estudios organizacionales giró alrededor del funcionalismo, el positivismo y el estructural-funcionalismo, lo que proporcionó una base al poder burocrático.

Durante las décadas de los sesenta y setenta, Argyris \& Schön (1978) realizó un estudio en el que observó y analizó la toma de decisiones a nivel ejecutivo en aproximadamente 50 organizaciones tanto públicas como privadas; en sus estudios obtuvo más de 50000 muestras de comportamiento gerencial, recopiladas en cerca de 200 reuniones. Sus conclusiones, contrario a lo que comúnmente se piensa, revelan que la mayoría de los directores generales son competitivos, pero inconscientemente fomentan el conformismo entre sus subordinados y desaniman a los que están dispuestos a tomar riesgos. Por ello, Argyris (1978) afirma que si un director ha alcanzado el éxito, difícilmente se encuentra dispuesto a formar a otro igual a él, pues sería como autodestruirse.

En consecuencia, la credibilidad de cualquier sistema administrativo depende del grado hasta el cual el director general y los demás ejecutivos de alto nivel están dispuestos a cambiar. Podemos observar que, desde su origen, en la gerencia de la empresa está la figura del poder, ya que tiene la posibilidad de imponer la propia voluntad dentro de una relación laboral, aun en contra de toda resistencia, imponiendo la estructura de autoridad dentro de la empresa y atendiendo a los sistemas de valores que las legitiman.

Por su parte, House y Browdith (1980) han elaborado "teorías contingentes"; según estos autores, el liderazgo se concibe como el proceso de dirigir e influir en las actividades del grupo en situaciones verdaderamente cambiantes e inestables, en donde todo es casual o accidental. En estos casos no puede existir una dirección estable, pues estas organizaciones requieren de estilos y sistemas de control no rutinarios. Toda dirección está influida por la época en la cual opera; las emergencias sociales producen ciertos énfasis en el tipo de dirección. Estas situaciones de emergencia se hacen palpables en periodos de caos o de crisis 


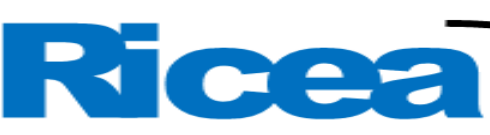

REVISTA IBEROAMERICANA DE CONTADURÍA, ECONOMÍA YADMINISTRACIÓN

ISSN $=2007-9907$

económicas; el grado de incertidumbre causado por los cambios políticos, tecnológicos y socioculturales incide en el estilo de dirección.

Los estudios de Tavistock — citados por Rice (1999)— hicieron hincapié sobre la relación del sistema tecnológico y el sociopsicológico en las minas inglesas de carbón. El método de trabajo consistió en cambiar métodos tradicionales de explotación por otros más avanzados. Tavistock desarrolló la siguiente relación de contingencia: si hay un cambio hacia una tecnología más adelantada, entonces deberán conservarse intactos los grupos de trabajo hasta donde sean posibles para lograr la relación efectiva de los objetivos propuestos.

Las variables contingenciales difieren según el tamaño de la organización, las tareas rutinarias, las tecnologías utilizadas, las diferencias individuales, las ambiciones, la autonomía y la tolerancia. Algunos autores explican a grandes rasgos que la dirección por contingencias se hace palpable ante una emergencia, y que bajo presión, confusión y caos los verdaderos jefes permanecen inamovibles porque enfrentan a los acontecimientos y guían a sus subordinados a soluciones satisfactorias.

Las contingencias son sucesos o circunstancias que se presentan de manera imprevista; por ello, el éxito de la dirección situacional depende de que los administradores se adapten a las situaciones, de ahí que deban ser flexibles. Sin embargo, ninguno de estos estudios consideró motivaciones, valores del empleado ni experiencia de los directivos. El enfoque de contingencias incorpora conceptos y técnicas de diferentes escuelas administrativas.

\section{Discusión}

En las condiciones contemporáneas, la concentración y la centralización del capital se dan sobre la base de la superioridad técnico-científica que poseen las grandes empresas que se encuentran dedicadas a los procesos productivos y que tienen mayores posibilidades de crédito dada su naturaleza oligopólica transnacional. La forma orgánica de dominación del capital financiero es el conjunto de compañías industriales, bancarias, de crédito, de seguros, de transportes, comerciales y de otro género coligadas al capital, que ha convertido a las empresas multinacionales en estados dentro del Estado.

En las sociedades corporativas, las decisiones se toman en función del número de votos que posee cada accionista; en contraste, en las sociedades cooperativas, cada socio tiene derecho a un voto. Si hemos de aceptar que el cooperativismo y el mutualismo están 


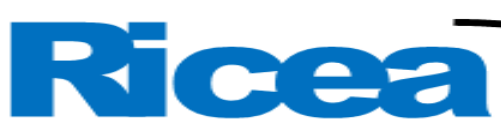

REVISTA IBEROAMERICANA DE CONTADURÍA, ECONOMÍA YADMINISTRACIÓN

$1 S S N=2007-9907$

basados en el ejercicio de la reciprocidad social, en una filosofía fundamentalmente humanista, el liberalismo rompe con toda tradición humanista, se desvincula de la idea de equidad y rinde culto a la industria y a la tecnología.

El mutualismo está basado en el ejercicio de la reciprocidad social, y parte de asociaciones voluntarias que dirigen una política para lograr la seguridad social y la búsqueda de un sistema de producción colectivo. La ética planteada como la elaboración de una forma de relación con uno mismo, que permite al individuo constituirse como sujeto de una conducta moral, es sinónimo del espíritu cooperativista mejor entendido, que procura el bienestar humano en todas sus modalidades.

Por tanto, debemos plantearnos la siguiente pregunta: ¿es posible el "liderazgo colectivo" como lucha por el control de las condiciones de productividad, de organización, de existencia de ámbitos de vida particulares? Además, ¿cómo reunir la fuerza necesaria para dar solución a la problemática que vive el mundo actual? Si lo político es la lucha por el control de las condiciones de cada ámbito de vida, si esta es la dirección, entonces esto le daría sentido a los movimientos y luchas por el reconocimiento de los derechos sociales, democráticos, de conciencia ideológica, ecológica, etcétera.

Todos los modelos de dirección son susceptibles de mejorar, pero la única manera de saberlo es proponiéndolos y aplicándolos. Para que México se inserte de manera vanguardista en el contexto mundial se deberán buscar modelos novedosos y pragmáticos en lo social, político, económico y administrativo que se adapten a nuestras características culturales e históricas.

En toda empresa y organización participa un círculo de personas interesadas en el mandato y sus ventajas, que colaboran en el ejercicio de los poderes imperativos y coactivos encaminados a la conservación de la dominación (Ballina, 1996, 2000, 2006, 2017, 2019, 2021).

La dominación — es decir, la probabilidad de hallar obediencia a un mandato determinado - Weber la clasifica en tres tipos puros: 1) dominación carismática, 2) dominación tradicional y 3) dominación burocrática. En la primera, el jefe patriarcal es el administrador, y se sustenta en el reconocimiento personal y su carisma. Asimismo, el cuadro administrativo es seleccionado por el principio del discipulado y de la fidelidad del séquito, y no reciben salarios, sino presentes honoríficos, donaciones, prebendas, etc.

En la administración patrimonial surgen los administradores organizados sobre principios tradicionales, leales y serviles: eunucos, cortesanos, monjes, maceguales, 


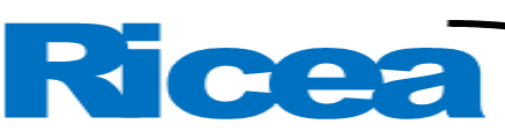

REVISTA IBEROAMERICANA DE CONTADURÍA, ECONOMÍA YADMINISTRACIÓN

ISSN $=2007-9907$

mayorales, capataces, etc. Se convierten en siervos de la dominación tradicional que participan en la dominación de masas trabajadoras o tributarias.

En la administración "burocrática" o "racional", surgen las figuras del “administrador”, jefe o managment, organizadas sobre principios burocráticos racionales tendientes a legitimar situaciones sociales, políticas, económicas y religiosas por parte de estratos sociales privilegiados.

Esta tipología que construyó Weber (1992) corresponde a los tipos ideales, constructos teóricos del "poder" y la "dominación”, elementos más importantes de la acción comunitaria. La dominación desempeña en casi todas sus formas —incluso donde menos se sospecha- un papel considerable. Así ocurre tanto en las sociedades ancestrales como en las formas modernas de burocracia. Weber constató que la estructura de dominación constituye, casi siempre y en gran medida, un factor económicamente importante y, en cierta forma, condicionado históricamente.

El concepto de "tipo ideal" o "tipo histórico" de la dominación en Weber no se utiliza de manera unívoca o casuística para señalar todas las formas de "dominar”. Por el contrario, estas son tan amplias que resultaría imposible aquí completar su casuística. Por ejemplo, el caso de México - por sus condiciones sui generis - no corresponde en sentido estricto al tipo burocrático identificado por este autor, sino que se asemeja más al corporativismo "como sistema de representación de intereses en el que las unidades organizadas jerárquicamente son diferenciadas, reconocidas o legalizadas por el gobierno (cuando no son creadas por este), a las que se les garantiza un determinado monopolio representativo dentro de sus respectivas categorías" (Schmitter, 1992, p. 11).

En cambio, el tipo de dominación carismática enunciada por Weber ocurre en la mayoría de las comunidades indígenas de México, donde existe una unidad inseparable entre cosmovisión, historia, territorio y cultura.

Conforme a diversos estudios se constata que, a lo largo de su historia, las comunidades indígenas en México han desarrollado diferentes modalidades de administración comunitaria, que reciben diferentes nombres según cada comunidad indígena, como el tequio, tequil, gozona, mano vuelta, fajina, guelaguetza, tarea, córima y trabajo de en medio, entre otras, donde cada comunidad articula distintas relaciones de poder y dominación, lo que genera variados niveles de legalidad y legitimidad. A través de estas organizaciones comunitarias se ha logrado construir los servicios comunitarios: agua, luz, caminos y otros servicios (Zolla, 2010). Al respecto, Weber (1969) establece la diferencia 


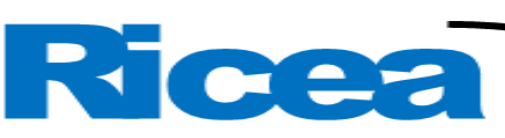

REVISTA IBEROAMERICANA DE CONTADURÍA, ECONOMIIA YADMINISTRACIÓN

ISSN $=2007-9907$

entre un caudillo elegido y un funcionario elegido: “el funcionario se comportará en todo como mandatario de su señor" (p. 716), mientras que el caudillo como responsable exclusivamente de sí mismo —o sea, mientras aspire con éxito a la confianza de aquellosactuará por completo según su propio arbitrio (democracia de caudillo), y no como el funcionario, conforme a la voluntad expresada o supuesta (en un "mandato imperativo") de los electores.

Habermas (1976) caracteriza a las sociedades tradicionales por la existencia de una autoridad que se impone por gerontocracia, rutina o por cuestiones de honor. En la sociedad tribal, lo político se encuentra por encima del especialista e impone respeto, ya que se decide colectivamente. En la sociedad moderna el papel se ha invertido, pues el especialista impone su lógica, y la política se subordina a la técnica: "La voluntad popular política es reemplazada por la legalidad inminente de las cosas que el hombre produce como ciencia y tecnología” (Habermas, 1976, p. 86).

En la dominación burocrática, los administradores se encuentran organizados a partir de principios racionales. Lo que Marx (1978) consideraba como alienación, Weber lo calificaba como "proceso de racionalización”. Erich Fromm (1997) continúa esta labor crítica frente a este tema central y señala que "las racionalidades carecen, en esencia, de ese carácter de descubrimiento y revelación (...); la racionalización no representa un instrumento para penetrar en la realidad, sino que constituye un intento post factum destinado a armonizar los propios deseos con la realidad exterior" (p. 234).

Desde el punto de vista de Weber (1992), el carisma en el liderazgo es, por definición, poco controlable desde arriba, por lo que establece la diferencia entre carisma y rutina. La estructura carismática —en oposición a la organización oficial burocrática - no reconoce nombramientos, carrera, ascensos o sueldos. El carisma solo estima determinaciones internas y límites propios. Su éxito depende de la corroboración del mismo hacia sus seguidores o secuaces. Consiguientemente, la situación de la autoridad carismática es por su misma naturaleza específicamente inestable.

Los líderes trabajan en posiciones de mucho riesgo y peligro. La autoridad "puramente carismática" no puede ser concebida en una "organización" o "empresa" en el sentido habitual de una asociación de hombres y cosas según principios de finalidad y medio. Los auxiliares de la autoridad carismática son seleccionados de acuerdo con el principio del discipulado y la fidelidad del séquito. El séquito o discipulado no recibe salarios, sino presentes honoríficos, botines, donaciones o “prebendas”. El carácter del carisma como poder 


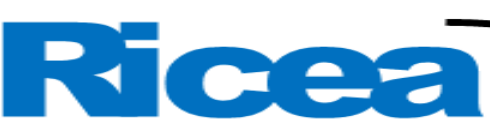

REVISTA IBEROAMERICANA DE CONTADURÍA, ECONOMÍA YADMINISTRACIÓN

ISSN $=2007-9907$

creativo decrece ante una dominación organizada en instituciones duraderas. El problema de la innovación y la transformación del liderazgo escapan a los valores de las organizaciones corporativas, que obligan y responsabilizan.

En oposición al modelo corporativo surge el cooperativo, emanado de autores como Saint-Simón, Charles Fourier, Esteban Cabet, Proudhon y Robert Owen, quienes criticaron el liberalismo de Adam Smith, David Ricardo, Augusto Comte y Herbert Spencer, y marcaron los principios teóricos del cooperativismo. Sin embargo, como no coincidían con la vía de la violencia señalada por el socialismo de la primera internacional, fueron calificados por los marxistas como "utópicos" (Ballina, 2000).

El cooperativismo está basado en el ejercicio de la reciprocidad social, y parte de asociaciones voluntarias que dirigen una política para lograr la seguridad social y la búsqueda de un sistema de producción colectivo.

A lo largo de su historia, el cooperativismo ha sido considerado y definido de múltiples formas, como doctrina política, modo de producción, etc., aunque es más que un concepto. En la actualidad se puede afirmar que el cooperativismo es un plan económico que forma parte importante de muchos Estados. Su desarrollo y difusión indican que podría modificar la estructura política de las sociedades que lo han implantado y que constituye una realidad para el siglo XXI.

En el enfoque estructural-funcionalista (Merton, 2002; Parson, 1977), los conceptos de poder y dominación se toman como similares, aunque Weber (1992) establece la diferencia:

El concepto de poder es sociológicamente amorfo. Todas las cualidades imaginables de un hombre y toda suerte de constelaciones posibles pueden colocar a alguien en la posición de imponer su voluntad en una situación dada. El concepto de dominación tiene, por eso, que ser más preciso y solo puede significar la probabilidad de que un mandato sea obedecido (p. 43).

De acuerdo con Weber, la dominación requiere de un cuadro administrativo, por incipiente que sea, para garantizar que el mandato se realice de manera pronta y automática; de lo contrario se pueda ejercer una coacción o reacción legal, física, moral o hierocrática. Así, la organización tiene una función reguladora hacia fuera, y a través de ella se caracteriza una relación de supremacía y subordinación, pues sus acciones permean a otras instancias. En tal sentido, la sociedad se desenvuelve bajo la influencia de diferentes organizaciones, como familia, iglesia, ejército, partidos políticos, sindicatos, oficinas gubernamentales, 


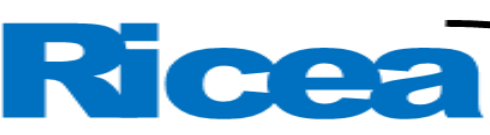

REVISTA IBEROAMERICANA DE CONTADURÍA, ECONOMÍA YADMINISTRACIÓN

$1 S S N=2007-9907$

prisiones, etc., que responden a necesidades y contextos específicos, por lo que toman diversas formas y representan distintos sistemas de valores dentro del complejo social.

Las denominadas teoría de la administración (management science) — surgida del contexto liberal anglosajón-y la teoría de la organización (organizations theory) (Hatch, 1997) consideran a las empresas (companies) y organizaciones (organizations) como entes similares. Son asumidas como comunidades o sociedades, relativamente permanentes, orientadas hacia un mismo objetivo y enfocadas en la acción organizacional, como conjunto de órganos y funciones (Merton, 2002; Parsons, 1977).

Al respecto, la teoría administrativa norteamericana homologa el concepto organización con el de empresa, aunque existe ambigüedad en el primero. Algunas veces es utilizado como función, es decir, consistente en agrupar actividades necesarias para el cumplimiento de objetivos; en otras, como estructura-diseño (decisión estratégica), o bien como actividad específica para diseñar y estructurar las tareas encaminadas a lograr las metas organizacionales (Dessler, 1996). En general, los autores que siguen esta teoría ignoran las relaciones de poder a nivel macro-micro, implícitas en las organizaciones y empresas.

La mayoría de los modelos del liderazgo situacional han tenido un éxito relativo en Estados Unidos debido a que las empresas estadounidenses han perdido competitividad frente a las asiáticas y europeas. La teoría Ouchi (1981) japonesa basada en la dirección participativa busca aumentar la productividad incrementando la intervención de los trabajadores mediante los "círculos de calidad" o de "excelencia", los grupos de trabajo autogestionario y los equipos de alto rendimiento. En Estados Unidos se ha intentado aplicar estos modelos, aunque con resultados muy restringidos.

En las teorías contemporáneas de la administración -enfoque operacional (McGregor, 1969) — y en la actual teoría de los sistemas —enfoque de las contingenciasprevalece la tolerancia y el eclecticismo, situación que se puede apreciar en los programas de estudio de las business school estadounidenses, donde predomina la confusión en el terreno teórico de la administración.

En la administración burocrática, los ejecutivos de alto nivel deben encargarse de decisiones que ya han sido tomadas conforme a los objetivos de la compañía. Por consiguiente, la dirección es la clave para el éxito de los programas de desarrollo de la organización. Los gerentes, inexorablemente, deben reforzar los sistemas de control administrativo vinculados a una disciplina, la cual consiste en la ejecución sólidamente racionalizada en la que se prescinde de toda crítica personal por parte del ejecutor. Su 


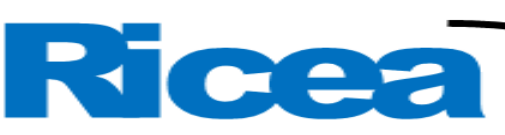

REVISTA IBEROAMERICANA DE CONTADURÍA, ECONOMÍA YADMINISTRACIÓN

ISSN $=2007-9907$

característica es la acción masificada, racionalmente uniforme; reemplaza al entusiasmo embriagador o la devoción por un caudillo personal. El devenir rutinario del carisma se debe a la necesidad de legitimar las situaciones sociales que extraen sus privilegios de los órdenes económico, social y político.

El surgimiento del director, del jefe y del administrador se intensifica en los países industrializados, donde el concepto de administración cambia sucesivamente de su campo tradicional y profesional a través del devenir rutinario del carisma y la necesidad de legitimar situaciones sociales, políticas, económicas y religiosas por parte de estratos privilegiados.

Las organizaciones burocráticas generalmente tratan de evitar riesgos, por lo que procuran suceder en el poder a gerentes entrenados, y no a líderes individuales. El liderazgo inevitablemente exige que se use el poder para influir en los pensamientos y actividades de los demás, mientras que los directores generalmente generan el conformismo.

En definitiva, en estos momentos en que se anuncia la cuarta transformación de la Republica, emprendida por el presidente López Obrador, se abre una nueva etapa llena de expectativas y se hace evidente la necesidad de un liderazgo político colectivo que incentive la reconstrucción nacional, desde una perspectiva ética y moral.

\section{Conclusiones}

En la teoría norteamericana de la administración cada día nos encontramos con nuevas fórmulas para lograr el "liderazgo"; sin embargo, en estos momentos de incertidumbre, dominados por expectativas y frustraciones colectivas, se hace evidente la falta de liderazgo político, económico, religioso, empresarial, etc.

La teoría norteamericana de la administración ha confundido los conceptos dirección, poder y autoridad con el liderazgo. El surgimiento de la administración moderna sugiere el advenimiento del gerente, jefe, director o manager como figura central de la organización burocrática, de la dirección rutinaria, en donde los ejecutivos de alto nivel deben encargarse de llevar a cabo decisiones que han sido tomadas previamente según los objetivos de poder y dominación imperantes.

Por consiguiente, una buena o mala dirección es la clave para el éxito de la empresa u organización. En términos generales, los modelos formales de la "dirección científica", “dirección participativa” y "dirección por contingencias” resultan dudosos debido a que no reconocen la verdadera dimensión del liderazgo, que es por definición poco controlable desde 


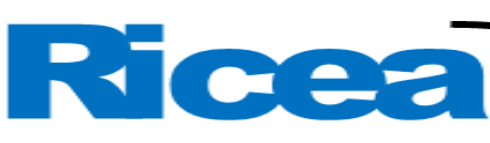

REVISTA IBEROAMERICANA DE CONTADURÍA, ECONOMÍA

arriba, desde la autoridad formal. En la mayoría de los casos, los verdaderos líderes no nacen o se forman, sino que las circunstancias los conforman, es decir, surgen a instancias de sus seguidores, en situaciones de crisis, de insatisfacción, indigencia, carencia o deseo.

La influencia que ejerce un líder para alternar estados de ánimo, evocar imágenes o esperanzas y establecer objetivos específicos no la satisface el gerente o la autoridad formal. El problema de la innovación y la transformación del liderazgo escapa a los valores de empresas y organizaciones que obligan y responsabilizan. El líder informal es el verdadero gestor del cambio en las organizaciones modernas, pues su legitimidad se basa en la autoridad moral, que se gana cotidianamente. En pocas palabras, el líder informal es quien finalmente podría echar a andar la maquinaria del cambio en la sociedad.

La fortaleza de las organizaciones y empresas cooperativas y comunitarias se manifiesta por el hecho de su trascendencia y supervivencia como entidades, que interpelan los valores "universales" que nacen de la modernidad y el eurocentrismo. El verdadero liderazgo surge en el cooperativismo, así como en empresas y organizaciones indígenas, donde encontramos una asociación entre ética, cosmovisión, productividad e identidad, atributos que generalmente no se hallan en las empresas y organizaciones corporativas.

Por tanto, es una tarea pendiente el estudio de casos empíricos que ejemplifiquen cómo ocurre el liderazgo en empresas y organizaciones comunitarias en México y en Latinoamérica. 


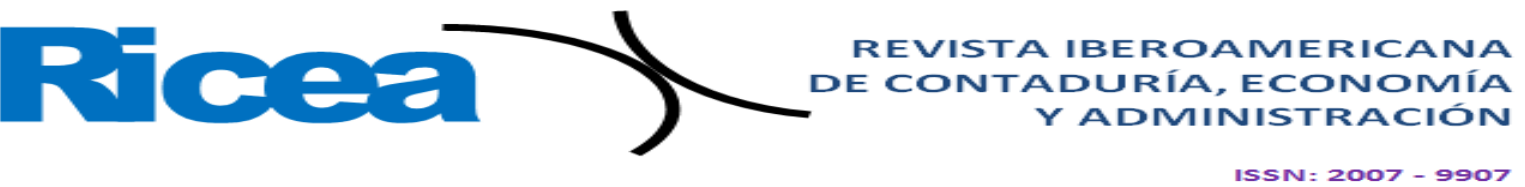

\section{Referencias}

Argyris \& Schön, D. (1978). Organizational learning a theory of action perspective. Reading, MA Addison-Wesley.

Aristóteles (trad. 1984). Política. Madrid, España: Centro de Estudios Constitucionales.

Ballina, F. (1996). Mitos y estereotipos en la teoría del liderazgo. Contaduría y Administración, (182), 43-54.

Ballina, F. (2000). Teoría de la administración, un enfoque alternativo. México. Mc Graw Hill.

Ballina, F. (2006). Diferencias en la administración premoderna, moderna posmoderna: propuestas para un debate en Latinoamérica. Problemas del Desarrollo, 37(144), 221-233.

Ballina, F. (2017). Ordenamiento administrativo de las organizaciones sociales de México: un problema de legalidad y legitimidad. XXII Congreso de Contaduría Universitaria. Ciudad de México, septiembre 26, 27 y 28 de 2017.

Ballina, F. (2019). Problemática epistemológica y sociológica de la administración. Revista Iberoamericana en Contaduría, Economía, Administración, 8(16).

Ballina, F. (2021). Empresas y organizaciones indígenas en Méjico: ¿modalidades alternativas de etnodesarrollo? Teuken Bidikay, 12(18).

Barnard, C. I. (1959). Las funciones de los elementos dirigentes. Madrid.

Blake, H. (1964). What is managerial grid? Definition and meaning, Gulf Publishing.

Dessler, G. (1976). Organización y administración situacional. Prentice-Hall.

Fayol, H. (1973). Administración industrial y general. México: Herrero.

Fiedler, F. (1967). A theory of leadership effectiveness. New York: Mc Graw Hill.

Fromm, E. (1997). El miedo a la libertad. Buenos Aires, Paidós.

Habermas, J. (1976). Ciencia y técnica como ideología. México, REI.

Hatch, J. (1997). Organization theory, modern, symbolic, and postmodern perspectives. United Kingdom: Oxford University Press.

Hersey, P. and Blanchard, K. (1982). Management of Organizational Behavior: Utilizing Human Resources. Prentice- Hall.

Homans, G. (1950). The human group. New York, United States: Harcourt, Brace and World. House, E. y Browdith, J. (1980). El comportamiento humano en la organización. México: Fondo Educativo Interamericano. 
Kahn, Wolfe, Quinn, Snoek, and Rosenthal (1964). Organizational stress: Studies in role conflict and ambiguity. New York: Wiley.

Leavitt, H. J. (1951). Some effects of certain communication patterns on group performance. Journal of Abnormal and Social Psychology, 46(1), 38-50.

Lewin, K. (1951). Field Theory of Social Science. Nueva York, United States: Harper and Row.

Lewin, K. (1968). Psychologie dynamique: Les relations humaines. Paris, France: Presses Universitaires de France.

Likert, R. (1967). The human organization. New York. Me Graw-Hill.

Mannheim, K. (1982). Libertad, poder y planificación democrática. México, FCE.

Maquiavelli, N. (1969). Le opere. Discursi sopra la prima deca di Tito Livio (Proemio I, II). Roma: Ed. Riuniti.

Marx, C. (1978). Contribución a la crítica de la economía política. México: Ediciones Populares.

Mayo, E. (1946). The Humans Problems of Industrial Civilization. Harvard University Graduate School.

Mayo, E. (1989). El temperamento humanista. Richard CS Transaction Publishers.

McGregor, D. (1969). El aspecto humano de las empresas. México: Diana.

Merton, R. K. (2002). Teoría y estructura sociales (4. ${ }^{\text {a }}$ ed.). México: FCE.

Michels, R. (1974). Los partidos políticos (tomos I y II). Buenos Aires, Argentina: Amorrortu.

Moliner, M. (1994). Diccionario del uso del español. Madrid: Gredos.

Ouchi, W. (1981). Theory Z: An elaboration of methodology and findings. J. Contemp. Bus, 11(1-2), 27-41.

Parker, M., Metcalf, H. C. and Urwick, L. (eds.) (1942). Dynamic Administration: The Collected Papers of Mary Parker Follett. New York, United States: Harper \& Brother Publishing.

Parsons, T. (1977). Social Systems and the Evolution of Action Theory. Nueva York: The Free Press.

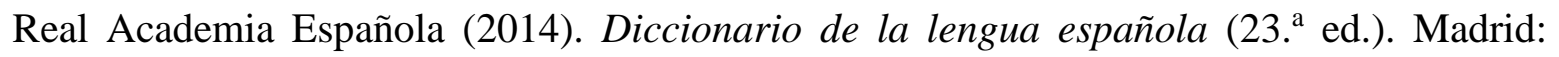
Espasa Calpe.

Rice, A. K. (1999). Tavistock, Learning for Leadership: Interpersonal and Intergroup Relations. New York, USA: British Library. 
Schmitter, P. (1992). Teoría del neocorporativsmo. México: Laberinto de Cristal.

Schreiber, J. (1969). El desafío americano. Barcelona: Plaza \& Janés, S. A. Editores.

Smith, A. (1976). La economía política clásica. Buenos Aires: Centro Editor de América Latina.

Stuart Mill, J. (2008). Principios de economía política. España: Síntesis.

Tannenbaum, R and Schmidt, W. (1958). How to Choose a Leadership Pattern. Retrieved from https://hbr.org/1973/05/how-to-choose-a-leadership-pattern

Taylor, F. (1973). Principios de la administración científica. México: Herrero.

Vroom, V. and Yetton, P. (1973). A New Look at Managerial Decision Making. . Retrieved from https://doi.org/10.2307/j.ctt6wrc8r

Weber, M. (1992). Economía y sociedad (tomos I y II). México, FCE.

Zaleznik, A. (1986). Administradores y líderes, ¿diferentes? México: Clásicos de la Administración de Harvard.

Zolla, C. (2010). Los pueblos indígenas de México: 100 preguntas (vol. 1) (2. a ed.). México: Universidad Nacional Autónoma de México. 